\title{
THE INFLUENCE OF USING AUDIOVISUAL MEDIA AND LEARNING MOTIVATION OF CHILDREN STORIES WRITING ABILITY
}

\author{
Salwaa Nadiya Alif, St. Y. Slamet, Yulianti \\ Universitas Sebelas Maret \\ 9fsalwaanaceper@gmail.com
}

\section{Article History}

accepted 09/07/2018

approved 01/08/2018

published 17/09/2018

\section{Keywords}

Audiovisual, Audio, Learning Motivation, Childern Stories Writing Ability

\begin{abstract}
The purpose of this research is to find out: (1) the different of writing children stories ability of students that teached by audiovisual media within audio media, (2) the different of writing children stories ablility of students that have the high learning motivationand low learning motivation, (3) the interaction between teaching media and learning motivation on the writing children stories ability. This research includes a Quasi Experimental methode design by $2 \times 2$ factorial design. Populaton of the research are all students at fourth grade elementary school in Laweyan district Surakarta in the academic year of 2017/2018. The selected sample are Bratan III No. 187 Elementary School and Karangasem II Elementary School. This research used Two Ways Anava data analysis technique. The result of this research are : (1) there is different of writing children stories ability of students that teached by audiovisual media within audio media with $F_{A}$ value $=15,70>$ $F_{0,051 ; 63}=3,481$; (2) there is different of writing children stories ablility of students that have the high learning motivationand low learning motivation with $F_{\mathrm{B}}$ value $=3,80>F_{0,05 ; 1 ; 63}=3,481$; (3) there is no interaction between teaching media and learning motivation on the writing children stories ability with $F_{A B}$ value $=$ $-0,10<F_{0,05 ; 1 ; 63}=3,481$.
\end{abstract}

Social, Humanities, and Education Studies (SHEs): Conference Series https://jurnal.uns.ac.id/shes

p-ISSN 2620-9284 e-ISSN 2620-9292 


\section{PENDAHULUAN}

Kemampuan menulis sangat penting di berbagai jenjang pendidikan maupun dalam kehidupan di masyarakat. Keberhasilan pelajar dalam mengikuti kegiatan belajar-mengajar di sekolah banyak ditentukan kemampuannya dalam menulis (Slamet, 2014: 108). Oleh karena itu, pembelajaran menulis tidak hanya menjadi dasar utama dalam pembelajaran mata pelajaran Bahasa Indonesia akan tetapi juga menjadi dasar utama pembelajaran mata pelajaran lainnya (Rukayah, 2013: 1).

Menulis dianggap sulit oleh siswa. Hal ini dikarenakan menulis merupakan kegiatan yang meembutuhkan kemampuan yang bersifat kompleks (Slamet, 2009: 72). Pernyataan tersebut didukung oleh pendapat Sulisworo dkk dalam jurnalnya Information Technologies and Learning Tools yang menyatakan bahwa menulis menjadi aktivitas kognitif yang sangat kompleks dan pada tingkat kalimat, penulis sebaiknya menguasai isi, susunan, struktur kalimat, perbendaharaan kata, tanda baca, dan ejaan.

Menulis cerita merupakan salah satu Kompetensi Dasar (KD) yang terdapat pada pembelajaran menulis Bahasa Indonesia di Sekolah Dasar (SD). Kenyataan di lapangan masih banyak siswa yang mengalami kesulitan dalam menulis cerita. Penelitian yang dilakukan oleh Izzati (2013) menunjukkan bahwa kemampuan menulis cerita di salah satu sekolah dasar di Laweyan Kota surakarta masih rendah dengan adanya prosentase prasiklus $62 \%$ sedangkan $36 \%$ dari 36 siswa dinyatakan belum tuntas. Salah satu faktor penyebab rendahnya kemampuan menulis yakni kemampuan yang dimiliki siswa dan kreativitas yang dimiliki oleh guru dikarenakan terkendala masalah media yang dipergunakan.

Kemampuan menulis cerita anak merupakan kemampuan menulis siswa di Sekolah Dasar (SD). Guru dituntut mampu menciptakan suasana kelas yang baik salah satunya dengan menggunakan media yang dapat menarik perhatian siswa agar keberhasilan tujuan dalam pembelajaran menulis cerita anak di Sekolah Dasar (SD) kelas IV tercapai. Menurut Susilana \& Riyana (2009:9) kegunaan media sebagai alat bantu yang akan menimbulkan gairah belajar. Dengan demikian penggunaan media dapat membawa pengaruh terhadap keberhasilan pencapaian tujuan pembelajaran. Salah satu alternatif untuk memotivasi siswa agar lebih terampil dalam menulis adalah menggunakan media audio visual.

Alasan utama pemilihan audio visual adalah guru memberikan kesempatan kepada siswa untuk menggunakan semua indra agar pembelajaran lebih bermakna. Ahmadi dan Supriyono (2013: 23-24) mengatakan bahwa cara setiap manusia dalam memperoleh tanggapan itu tidaklah sama. Salah satu tipe tanggapan adalah tipe campuran yang artinya semua indra memiliki kemampuan seimbang. Jadi melalui media audio visual dalam menulis cerita anak siswa dapat menggunakan indra penglihatan, pendengaran, dan motoriknya. Terlebih, siswa usia SD tentu senang melihat gambar-gambar yang bergerak disertai suara yang menarik, sehingga dapat tercipta suasana pembelajaran yang menyenangkan.Penggunaan media audio visual dalam pembelajaran menulis cerita anak memiliki langkah-langkah sebagai berikut: (1) menyiapkan media audio visual yang akan ditampilkan dan perlengkapan media ini sebelum pembelajaran, (2) menampilkan audio visual berupa video, (3) melakukan tanya jawab seputar cerita anak yang telah ditampilkan, (4) menyusun kerangka karangan cerita anak sesuai video cerita anak yang ditampilkan, (5) mengevaluasi kerangka bersama guru, (6) membuat karangan terpadu dari kerangka cerita anak, (7) karangan cerita anak dikumpulkan. 
Salah satu faktor yang mempengaruhi kegiatan belajar mengajar adalah motivasi. Godzicki L det al. dalam Jurnalnya Increasing Motivation and Engagement in Elementary and Middle School Students Through Technology-Supported Learning Environment (2013: 108) menyatakan bahwa siswa lebih termotivasi dan terlibat dengan aktif dalam pembelajaran ketika menggunakan teknologi. Secara keseluruhan, perilaku siswa lebih menyenangkan terhadap tujuan pembelajaran ketika menggunakan teknologi. Teknologi pendukung pembelajaran lingkungan meningkatkan motivasi dan keterlibatan siswa 9\% setelah masa intervensi. Berdasarkan dari penelitian tersebut, peneliti menyimpulkan bahwa teknologi dapat meningkatkan motivasi belajar siswa yang berpengaruh pada prestasi akademik siswa. Hal tersebut juga berlaku untuk tingkat kemampuan siswa dalam menulis cerita anak.

Motivasi merupakan proses internal yang kompleks yang tidak bisa diamati secara langsung, melainkan bisa dipahami melalui kerasnya seseorang dalam mengerjakan sesuatu. Sardiman (2014: 75) mengatakan bahwa motivasi adalah keseluruhan daya penggerak di dalam diri siswa yang menimbulkan kegiatan belajar, yang menjamin kelangsungan dari kegiatan belajar dan memberikan arah pada kegiatan belajar, sehingga tujuan yang dikehendaki dapat tercapai. Jika siswa yang memiliki motivasi yang tinggi maka siswa berkeinginan mempelajari materi menulis cerita anak, sehingga akan mempengaruhi kemampuannya dalam menulis cerita anak. Oleh sebab itu, motivasi belajar siswa perlu ditumbuhkan dan ditingkatkan.

Permasalahan penelitian ini antara lain : (1) apakah ada perbedaan kemampuan menulis cerita anak antara siswa yang diajarkan dengan media audio visual dengan siswa yang diajarkan dengan media audio?, (2) apakah ada perbedaan kemampuan menulis cerita anak antara siswa yang memiliki motivasi belajar tinggi dengan siswa yang memiliki motivasi belajar rendah?, (3) apakah ada interaksi antara media pembelajaran dan motivasi belajar siswa terhadap kemampuan menulis cerita anak?.

\section{METODE}

Penelitian ini termasuk penelitian jenis penelitian dengan pendekatan kuantitatif eksperimental semu dengan desain faktorial $2 \times 2$. Populasi dalam penelitian ini adalah seluruh siswa kelas IV SD Negeri di Kecamatan Laweyan Kota Surakarta tahun pelajaran 2017/2018. Sampel yang digunakan dalam penelitian ini adalah sebagian siswa kelas IV SD Negeri di Kecamatan Laweyan Kota Surakarta tahun ajaran 2017/2018, yaitu 30 siswa kelas IV SD N Bratan III No. 178 sebagai kelompok eksperimen dan 37 siswa kelas IV SD N Karangasem II sebagai kelompok kontrol. Teknik pengambilan sampel yang digunakan dalam penelitian ini adalah cluster random sampling. Teknik pengumpulan data yang digunakan dalam penelitian ini ada dua macam, yaitu tes dan nontes. Teknik analisis data yang digunakan pada penelitian ini adalah Analisis Variansi Dua Jalan (Anava Two Ways) pada taraf signifikansi 0,05 . Uji prasyarat analisis yang digunakan adalah uji keseimbangan dengan uji-t, uji normalitas dengan uji Liliefors, serta uji homogenitas dengan uji Barlett. Uji lanjut pasca anava menggunakan uji Scheffe untuk mengetahui pengaruh variabel lebih baik. 


\section{HASIL DAN PEMBAHASAN}

Sebelum dilakukan uji analisis data, uji prasyarat analisis dilakukan terlebih dahulu yaitu uji normalitas, uji homogenitas, dan uji keseimbangan. Uji keseimbangan dilakukan untuk mengetahui apakah sampel yang digunakan dalam penelitian memiliki kemampuan awal yang sama atau tidak.Uji keseimbangan ini dimabil dari data hasil pretest.

Tabel 1. Rataan dan Variansi Data Prestest

\begin{tabular}{|c|c|c|c|}
\hline Kelompok & Jumlah Siswa & Rata-rata & Simpangan Baku \\
\hline Eksperimen & 30 & 61,16 & 8,56 \\
\hline Kontrol & 37 & 57,56 & 10,78 \\
\hline
\end{tabular}

Berdasarkan Tabel 1 diketahui bahwa rata-rata skor pretest kelompok eksperimen sebesar 61,16 dengan simpangan baku 8,56; sedangkan rata-rata skor pretest kelompok kontrol sebesar 57,56 dengan simpangan baku 10,78.

Tabel 2. Harga Analisis Statistik Uji Normalitas Skor Pretest

\begin{tabular}{|c|c|c|c|}
\hline Kelompok & $\mathrm{L}_{\text {maks }}$ & $\mathrm{L}_{\text {tabel }}$ & Keputusan Uji \\
\hline Eksperimen & 0,132 & 0,161 & $\mathrm{H}_{0}$ diterima \\
\hline Kontrol & 0.095 & 0,145 & $\mathrm{H}_{0}$ diterima \\
\hline
\end{tabular}

Berdasarkan Tabel 2 diketahui bahwa masing-masing sampel berasal dari populasi yang berdistribusi normal yang ditunjukkan oleh harga $L_{\text {hitung }}$ untuk masing-masing sampel tidak melebihi harga tabel sehingga $\mathrm{H}_{0}$ diterima.

Hasil perhitungan uji homogenitas dengan rumus uji Barlett dengan statistika uji Chi-kuadrat $\left(\mathrm{x}^{2}\right)$ dan taraf signifikansi 0,05 diperoleh nilai statistika uji dari kelompok eksperimen dan kelompok kontrol adalah $\mathrm{x}^{2}$ hitung $=1,71$ dan $\mathrm{x}_{\text {tabel }}^{2}=3,841$ sehinga $\mathrm{H}_{0}$ diterima karena $\mathrm{x}^{2}{ }_{\text {hitung }}=1,71<\mathrm{x}_{\text {tabel }(0,05 ; 1)}$. Hal tersebut berarti kedua kelompok homogen.

Berdasarkan uji normalitas dan uji homogenitas diperoleh bahwa kedua sampel berasal dari populasi berdistribusi normal dan variansinya homogen maka selanjutnya dilakukan uji-t. Hasil uji keseimbangan dengan rumus uji-t diperoleh $t_{\text {hitung }}=$ 0,148 berdasarkan perhitungan, $t_{\text {hitung }}=0,148 \notin D K=\{t \mid t<-1,98$ atau $t>1,98\}$, maka $\mathrm{H}_{0}$ diterima. Sehingga dinyatakan bahwa kemampuan awal kedua sampel dalam keadaan seimbang atau kedua sampel mempunyai kemampuan awal yang sama 
Tabel 3. Hasil Analisis Uji Normalitas

\begin{tabular}{|c|c|c|c|}
\hline Sumber & $\mathrm{L}_{\text {maks }}$ & $\mathrm{L}_{\text {tabel }}$ & Keputusan Uji \\
\hline Kelompok Eksperimen & 0,123 & 0,161 & $\mathrm{H}_{0}$ diterima \\
\hline Kelompok Kontrol & 0,1350 & 0,1456 & $\mathrm{H}_{0}$ diterima \\
\hline Motivasi Belajar Tinggi & 0,148 & 0,156 & $\mathrm{H}_{0}$ diterima \\
\hline Motivasi Belajar Rendah & 0,1067 & 0,1497 & $\mathrm{H}_{0}$ diterima \\
\hline
\end{tabular}

Berdasarkan Tabel 3 dapat diketahui bahwa harga $L=\operatorname{maks}\left\{\left|F\left(Z_{i}\right)-S\left(Z_{i}\right)\right|\right\}$ pada kelompok eksperimen, kelompok kontrol, motivasi belajar tinggi, dan motivasi belajar rendah tidak melebihi harga $L_{\text {tabel }}$ sehingga $H_{0}$ diterima. Hal ini menunjukkan bahwa sampel penelitian berasal dari populasi yang berdistribusi normal.

Tabel 4. Hasil Analisis Statistik Uji Homogenitas

\begin{tabular}{|c|c|c|c|}
\hline Sumber & $\mathrm{X}^{2}$ hitung & $\mathrm{X}_{\text {tabel }}^{2}$ & Keputusan Uji \\
\hline $\begin{array}{c}\text { Kelompok Eksperimen } \\
\text { dan Kontrol }\end{array}$ & 0,00023025 & 3,841 & $\mathrm{H}_{0}$ diterima \\
\hline $\begin{array}{c}\text { Motivasi Belajar Tinggi } \\
\text { dan Rendah }\end{array}$ & 0,0087 & 3,841 & $\mathrm{H}_{0}$ diterima \\
\hline Antar Sel & 0,74 & 7,815 & $\mathrm{H}_{0}$ diterima \\
\hline
\end{tabular}

Nilai statistik uji homogenitas kelompok eksperimen dan kelompok kontrol adalah $\mathrm{x}_{\text {hitung }}^{2}=0,00023025$ sedangkan $\mathrm{x}_{\text {tabel }}^{2}$ untuk tingkat signifikansi 0,05 adalah $x_{0,05 ; 1}=3,841$; karena $x^{2}$ hitung $=0,00023025<x_{0,05: 1}=3,841$ maka $H_{0}$ diterima. Hal ini menunjukkan bahwa kedua kelompok berasal dari populasi yang variansinya homogen.

Nilai statistik uji homogenitas kelompok motivasi belajar tinggi dan motivasi belajar rendah adalah $x^{2}$ hitung $=0,0087$ sedangkan $x_{\text {tabel }}^{2}$ untuk tingkat signifikansi 0,05 adalah $x_{0,05 ; 1}=3,841$; karena $x^{2}{ }_{\text {hitung }}=0,0087<x_{0,05 ; 1}=3,841$ maka $H_{0}$ diterima. Hal ini menunjukkan bahwa kedua kelompok berasal dari populasi yang variansinya homogen.

Nilai statistik uji homogenitas antar sel adalah $x^{2}$ hitung $=0,74$ sedangkan $x_{\text {tabel }}^{2}$ untuk tingkat signifikansi 0,05 adalah $x_{0,05 ; 3}=7,815$; karena $x^{2}$ hitung $=0,74<x_{0,05 ; 3}=$ 7,815 maka $H_{0}$ diterima. Hal ini menunjukkan bahwa kedua kelompok berasal dari populasi yang variansinya homogen. 
Tabel 5. Hasil Analisis Variansi Dua Jalan dengan Sel Tak Sama

\begin{tabular}{|c|c|c|c|c|c|}
\hline $\begin{array}{c}\text { Sumber } \\
\text { Varians }\end{array}$ & JK & DK & RJK & $\mathbf{F}_{\text {hitung }}$ & $\mathbf{F}_{\text {tabel }}$ \\
\hline Antar A & $3.586,58$ & 1 & $3.586,58$ & 15,70 & 3,481 \\
\hline Antar B & 870,23 & 1 & 870,23 & 3,80 & 3,481 \\
\hline Interaksi A×B & $-23,03$ & 1 & $-23,03$ & $-0,10$ & 3,481 \\
\hline Dalam & $14.390,85$ & 63 & 228,42 & - & - \\
\hline Total & $18.824,62$ & 66 & - & - & - \\
\hline
\end{tabular}

Berdasarkan Tabel 5 menunjukkan bahwa : (1) Pada efek baris (A) didapat nilai $F_{A}=15,70$, sedangkan $F_{0,05 ; 63}=3,481$. Ternyata $F_{A}>F_{\text {tabel }}$, sehingga $H_{0 A}$ ditolak. Hal ini menunjukkan adanya perbedaan kemampuan menulis cerita anak antara siswa yang diajar dengan media audio visual dan siswa yang diajar dengan media audio; (2) Pada efek kolom (B) didapat nilai $F_{A}=3,80$, sedangkan $F_{0,05 ; 63}=3,481$. Ternyata $F_{A}>$ $F_{\text {tabel}}, H_{0 B}$ ditolak. Hal ini menunjukkan adanya perbedaan kemampuan menulis cerita anak antara siswa yang memiliki motivasi belajar dengan siswa yang memiliki motivasi belajar rendah; (3) Pada efek interaksi $(A B)$ didapat nilai $F_{A}=-0,10$, sedangkan $F_{0,05 ; 63}=$ 3,481. Ternyata $F_{A}>F_{\text {tabel}}, H_{O A B}$ diterima. Hal ini menunjukkan bahwa tidak adanya interaksi antara media pembelajaran dan motivasi belajar terhadap kemampuan menulis cerita anak.

Berdasarkan hasil perhitungan Analisis Variansi Dua Jalan (Anava), menunjukkan bahwa koefisien $F_{A}$ dan $F_{B}$ terdapat perbedaan yang signifikan, sedangkan koefisien $F_{A B}$ menunjukkan tidak terdapat interaksi antara media pembelajaran dan motivasi belajar sehngga tidak diperlukan uji lanjut pasca anava. Hasil dari rerataan skor kemampuan menulis cerita anak anatar baris maupun rerataan anatar kolom terangkum pada Tabel 6 berikut ini:

Tabel 6. Rataan Masing-Masing Sel

\begin{tabular}{|c|c|c|c|}
\hline \multirow{2}{*}{$\begin{array}{c}\text { Media } \\
\text { Pembelajaran }\end{array}$} & \multicolumn{2}{|c|}{ Motivasi Belajar } & \multirow{2}{*}{ Rataan Marginal } \\
\cline { 2 - 4 } & Tinggi $\left(\mathrm{B}_{1}\right)$ & Rendah $\left(\mathrm{B}_{2}\right)$ & \\
\hline Audio Visual $\left(\mathrm{A}_{1}\right)$ & 80,06 & 69,64 & 75,2 \\
\hline Audio $\left(\mathrm{A}_{2}\right)$ & 61,62 & 59,61 & 60,48 \\
\hline Rataan Marginal & 70,84 & 63,62 & \\
\hline
\end{tabular}

Hipotesis pertama $\left(\mathrm{H}_{\mathrm{OA}}\right)$ ditolak sehingga diperoleh rataan marginal baris $A_{1}$ lebih besar daripada rataan marginal baris $A_{2}$ yaitu 75,2 $>60,48$. Hal tersebut menunjukkan bahwa kemampuan menulis cerita anak siswa yang diajar menggunakan media audio visul lebih baik dari siswa yang diajar dengan media audio. Hipotesis kedua $\left(\mathrm{H}_{0 \mathrm{~A}}\right)$ ditolak sehingga diperoleh rataan marginal kolom $\mathrm{B}_{1}$ lebih besar daripada 
rataan baris $B_{2}$ yaitu $70,84>63,62$. Hal tersebut menunjukkan bahwa kemampuan menulis cerita anak antara siswa yang memiliki motivasi belajar tinggi lebih baik dari siswa yang memiliki motivasi belajar rendah. Hipotesis ketiga $\left(\mathrm{H}_{\mathrm{OAB}}\right)$ diterima, sehingga tidak perlu dilakukan uji lanjut pasca anava antar sel.

Berdasarkan hasil analisis data penelitian menyatakan bahwa tidak ada interaksi antara media pembelajaran dan motivasi belajar terhadap kemampuan menulis cerita anak. Hal ini berarti bahwa kemampuan menulis cerita anak dipengaruhi oleh media pembelajaran. Semakin baik media pembelajaran yang digunakan, maka semakin tinggi kemampuan menulis cerita anak setiap kelompok siswa, tanpa memperhatikan tinggi rendahnya motivasi belajar. Alasan yang dapat dikemukakan mengapa tidak ada interaksi antara media pembelajaran dan motivasi belajar terhadap kemampuan menulis cerita anak karena: (1) kondisi kelas yang berbeda dapat mempengaruhi hasil belajar siswa, (2) guru memiliki tingkat keterampilan yang berbeda-beda yang dapat mempengaruhi pemahaman siswa dalam materi menulis cerita anak, (3) adanya variabel/faktor lain yang ikut mempengaruhi hasil kemampuan menulis cerita anak seperti kondisi siswa tentang minat siswa, bakat siswa, perhatian orang tua, dan sebagainya, (4) terbatasnya waktu yang diberikan pihak sekolah dalam pengambilan data sehingga kurang maksimal.

Berdasarkan temuan-temuan tersebut maka dapat dibuktikan bahwa media pembelajaran audio visual terbukti secara signifikan dapat mempengaruhi kemampuan menulis cerita anak pada siswa kelas IV Sekolah Dasar.

\section{SIMPULAN}

Berdasarkan hasil analisi data dan pembahasan di atas, dapat disimpulkan bahwa dalam penelitian ini menunjukkan : (1) Terdapat perbedaan kemampuan menulis cerita anak siswa yang diajar dengan media audio visual dan siswa yang diajar dengan media audio; (2) Terdapat perbedaan kemampuan menulis cerita anak siswa yang memiliki motivasi belajar tinggi dan siswa yang memiliki motivasi belajar rendah; (3) Tidak terdapat interaksi antara media pembelajaran dan motivasi belajar terhadap kemampuan menulis cerita anak.

\section{DAFTAR PUSTAKA}

Ahmadi, A. \& Supriyono, W. (2004). Psikologi Belajar. Jakarta : Rineka Cipta.

Godzicki, L., Godzicki, N., Krofel, M., \& Michaels, R. (2013, Mei). Increasing Motivation and Engagement in Elementary and Middle School Student Trough Technology-Supported Learning Environments. ERIC. Retrieved 30 November, 2017, from https://eric.ed.gov//id=ED541343.

Izzati, A. R. (2013). Peningkatan Aktivitas dan Kemampuan Menulis Cerita Bahasa Indonesia Melalui Strategi Picture And Picture pada Siswa Kelas IV di SD Negeri Karangasem 2 Surakarta Tahun Pelajaran 2012/2013. Naskah Publikasi. Retrived 28 November, 2017, from http://eprint.ums.ac.id

Rukayah. (2013). Pedoman Pelaksanaan Pembelajaran Menulis dengan Pendekatan Whole Language di Sekolah Dasar. Surakarta: UNS Press.

Sardiman, M. A. (2014). Interaksi dan Motivasi Belajar Mengajar. Jakarta: Rajawali Pers.

Slamet, St, Y. (2009). Dasar-Dasar keterampilan Berbahasa Indonesia. Solo: UNS Press.

Slamet, St, Y. (2014). Pembelajaran Bahasa dan Sastra Indonesia di Kelas Rendah dan Kelas Tinggi Sekolah Dasar. Solo: UNS Press.

Susilana, R. \& Riyana, C. (2009). Media Pembelajaran: Hakikat, Pengembangan, Pemanfaatan, dan Penilaian. Bandung: CV Wacana Prima. 